\title{
Educação confessional presbiteriana: do pragmatismo protestante ao calvinismo, um longo caminho
}

\author{
Presbyterian confessional education: the long road \\ from protestant pragmatism to the calvinism
}

\section{Antonio Maspoli de Araujo Gomes*}

Universidade Presbiteriana Mackenzie, São Paulo, SP, Brasil

\section{Resumo}

O sistema Mackenzie de Ensino surge em 1870 com o nascimento da Escola Americana, uma instituição paroquial, calvinista confessional. A confessionalidade, contudo, é implantada somente pela reforma dos Estatutos da Universidade, em 1999, quando o nome Universidade Mackenzie é mudado para Universidade Presbiteriana Mackenzie. A partir da análise da literatura, os objetivos deste artigo são: a) inventariar as raízes históricas da educação protestante presbiteriana; b) analisar o processo de transformação recente da educação presbiteriana, na Universidade Presbiteriana Mackenzie, de educação pragmática para educação confessional. O método de pesquisa utilizado é o histórico crítico combinado com princípios da observação participante.

\footnotetext{
AMAG: PhD em História das Ideias, e-mail: maspolipeixe@yahoo.com.br
} 
Palavras-chave: Confessionalidade. Educação Presbiteriana. Sistema Mackenzie de Ensino. Calvinismo. Educação Protestante.

\section{Abstract}

The Mackenzie teaching system was created in 1870 with the birth of what was at the time named American School. The American School was a private, confessional Christian Calvinist institution. Its confessionalism, however, was only established at the university level in 1999 with the changes made to the general statute of the university when its name was changed to Universidade Presbiteriana Mackenzie (Mackenzie Presbyterian University). According to the literature review, the objectives of this article are: a) listing the historical roots of the Protestant Presbyterian education and b) analyzing the recent transformation at Mackenzie Presbyterian University from a pragmatic education to a confessional education system. The research method used is critical historical combined with principles of participant observation.

Keywords: Confessionalism. Presbyterian Education. Mackenzie Education System. Calvinism. Protestant Education.

\section{Estudos sobre a educação protestante no Brasil}

A educação dos protestantes presbiterianos, no Brasil, foi ventilada, de uma forma ou de outra, por todos aqueles autores que se ocuparam da história do protestantismo. Nessas obras, a educação protestante aparece mais como pano de fundo dos fatos sociais relacionados à importação da denominação presbiteriana do que como seu objeto central de pesquisa e discussão.

O estudo sobre a educação protestante iniciou-se com autores de língua inglesa. Dentre estes, destacam-se: Paul Andress (1951), An Educational Approach to the Work of the Protestant Church in Latin America; Jerry S. Key (1965), The Rise and Development of Baptist Theological Education in Brazil, 1881-1963: A Historical and Interpretative Survey; Lory C. Sisk (1974), The History of Agnes Erskine College in Brazil, 1904-1970. 
No Brasil, os estudos sobre a educação protestante presbiteriana são relativamente recentes. Hélio Oscar Moraes Garcia (1968) narra o episódio de estatização do Mackenzie pelo governador Laudo Natel. Uma história oficial do Colégio Protestante, célula máter da Escola Americana e do Mackenzie College, 1952, foi contada por Benedito Novaes Garcez (1970). Jether Pereira Ramalho (1976) realizou uma pesquisa sobre as várias denominações protestantes (metodistas, presbiterianos, batistas etc.) ao sistema educacional brasileiro. Maria Lucia Barbanti (1977) avalia a influência da educação protestante na província de São Paulo. Uma tese de doutorado sobre os aspectos históricos e culturais da educação presbiteriana foi defendida por Osvaldo Henrique Hack (1985). Yone Quartin (1995) destaca, em sua pesquisa, a participação do Mackenzie na Revolução Constitucionalista de 1932. O historiador M. Albino (1996) inventaria a educação protestante no Colégio Internacional, um colégio confederado, para a educação em Campinas e região.

Antonio Maspoli de Araujo Gomes (2000) analisa a cooperação do espírito protestante presbiteriano para a constituição do Mackenzie College e a formação da mentalidade empresarial de São Paulo. Marcel Mendes (1999) apresenta a história do Mackenzie College, especialmente da Escola de Engenharia. Roque Theophilo Júnior (2002) retrata os principais documentos históricos do Mackenzie. Osvaldo Henrique Hack (2003) examina as raízes históricas da confessionalidade do Mackenzie. Marcel Mendes (2005) avalia também aspectos recentes da Universidade Presbiteriana Mackenzie, até 1973, em suas relações com a política e a sociedade brasileira. Marcel Mendes et al. (2013) narram a história do Mackenzie desde as suas origens até a atualidade. Bendito Aguiar Neto e Reynaldo Cavalheiro Marcondes (2014) estudam a Universidade Presbiteriana Mackenzie, no contexto dos desafios enfrentados pela universidade contemporânea.

Os autores que pesquisaram a educação presbiteriana, no Brasil, relacionam em suas teses as escolas protestantes ao projeto missionário presbiteriano de evangelização das massas. Este pesquisador, todavia, considera que a educação presbiteriana foi condicionada também por outros fatores, tais como: a) O projeto educacional missionário, presbiteriano, norte-americano, em São Paulo, não pode ser dissociado 
do próprio projeto norte-americano de expansão: o destino manifesto de meados do século XIX (GOMES, 2000); b) O Colégio Protestante fundado na cidade São Paulo nasce inicialmente vinculado à igreja e ao idealismo missionário-presbiteriano de evangelização do Brasil e, posteriormente, após a sua vinculação ao complexo denominado Universidade do Estado de Nova York, sob a direção do comerciante, médico e educador Horace Lane, assume uma postura pragmática, própria da sociedade norte-americana, voltando-se para a formação da mentalidade empresarial de São Paulo (GOMES, 2000); c) O relativo sucesso das escolas presbiterianas em São Paulo deveu-se mais ao pragmatismo de alguns educadores presbiterianos do que ao impulso evangelístico dessas escolas; tal pragmatismo atraiu republicanos, imigrantes judeus, ingleses, italianos e norte-americanos e negociantes da sociedade paulista, especialmente por meio da Escola Normal, Escola de Comércio e Escola de Engenharia. Das mais de sessenta escolas presbiterianas fundadas na segunda metade do século XIX por missionários norte-americanos no Sudeste, apenas o Mackenzie sobreviveu (CORREA, 1980); d) A confessionalidade calvinista presbiteriana, a cosmovisão educacional presbiteriana nasce junto com o Colégio Protestante, atual Colégio Mackenzie, mas a confessionalidade na Universidade Presbiteriana é de constituição recente, datando de 1999 (HACK, 2003).

A partir da análise da literatura, os objetivos desta pesquisa são: a) inventariar as raízes histórico-teológicas da educação protestante presbiteriana; b) analisar o processo de transformação recente da educação presbiteriana, na Universidade Presbiteriana Mackenzie, de educação pragmática para educação confessional.

A pesquisa utilizou-se do método misto: método histórico e o método da observação participante. O método histórico, também chamado de método crítico ou crítica histórica, compreende duas operações a saber: análise e síntese. A análise compreende, por sua vez, quatro operações: a heurística, as críticas interna e externa, e a hermenêutica. A observação participante, adotada pelos antropólogos e também por médicos e psicólogos, consiste em uma participação efetiva na vida e nas atividades dos sujeitos a serem observados, em sua vida cotidiana. É, antes de tudo, uma aprendizagem e um modo de trabalho. Nesse processo, o observador 
é sujeito e objeto da pesquisa, juntamente com aquele a quem ele observa (MALINOWSKI, 1997).

\section{Raízes históricas da educação presbiteriana no Brasil}

A influência da Reforma do século XVI sobre a educação é inegável. Esse movimento religioso será um dos fatores importantes na ascensão de uma cultura escrita, no mundo ocidental, após a descoberta da imprensa. A Igreja Reformada vai definir a religião a partir de uma relação íntima e pessoal com Deus, e essa comunhão com o sagrado se dará pela mediação do texto bíblico, isto é, por intermédio do contato do cristão com os textos da Bíblia. A Bíblia é elevada pela Reforma protestante à categoria de revelação especial, a palavra de Deus, a única regra de fé e prática. Desde a Reforma protestante, no ato de batismo, os calvinistas prometem ao oficiante ensinar seu filho a ler e escrever, para que, adultos, leiam e compreendam a Bíblia (ANDERSON et al., 1953).

Lutero mesmo empenhou a sua vida na tradução da Bíblia para a língua alemã, a fim de colocar a Bíblia nas mãos do povo. Pouco ou nada adiantava colocar a Bíblia nas mãos de um povo analfabeto, mesmo com a vulgarização dos textos escritos pela invenção da imprensa. A evangelização dos povos, imperativo da Igreja Reformada, não seria levada adiante sem uma estratégia de alfabetização dos leigos e educação do clero (BRENTANO, 1968).

As tendências para a Reforma se tinham notado por muitos anos, mas podemos afirmar que a Reforma nasceu em 31 de outubro de 1517, quando Martinho Lutero (1483-1546) afixou as suas 95 teses à porta da Igreja de Todos os Santos, na cidade de Wittemberg. Da Alemanha rapidamente a Reforma se espalhou para outros países da Europa, como França, Inglaterra, Suíça etc. Na Suíça, chega pela eloquência de Ulrich Zuínglio (1484-1531). A Suíça, ávida pela sua independência, apoiou Zuínglio. Assim como na Alemanha, também na Suíça, na França, na Holanda e na Escócia os reformadores promoveram a educação pelo binômio igreja-escola (IRWIN, 1947).

A Reforma Religiosa do século XVI teve em João Calvino um dos seus importantes teólogos. A herança calvinista é a Igreja Reformada, 
aqui no Brasil identificada como Igreja Presbiteriana. Até chegar ao Brasil, a trajetória da Igreja Reformada percorreu um longo caminho. Iniciada em Genebra, na Suíça, em 1536, no terceiro quartel do século XVI, John Know, um discípulo de Calvino, leva a Reforma para a Escócia, berço do presbiterianismo; da Escócia, a Igreja Reformada é transplantada pelos pais fundadores dos Estados Unidos. E vai para a América do Norte (MENDONÇA, 1995, p. 71-79). A fim de promover a sustentação da Reforma calvinista, Calvino funda a Academia de Genebra, que influenciou o sistema universitário suíço posterior. A partir da Academia de Genebra, a Reforma formou líderes para a nascente Igreja Reformada na Holanda, Bélgica, Escócia, Inglaterra etc. A Igreja Reformada da Escócia é a base da igreja das colônias inglesas na América do Norte (LESSA, 1938).

O sistema de doutrina calvinista é complexo e deriva do pensamento de Santo Agostinho em quase sua totalidade. Esse sistema encontra-se exposto nos comentários bíblicos de João Calvino (1967) e, principalmente, em sua principal obra de teologia sistemática, intitulada Institución de la Religión Cristiana. Posteriormente, em 1636, tal sistema de doutrina foi sistematizado pela Confissão de Fé de Westminster.

O Protestantismo brasileiro teve suas origens nos interesses comerciais de ingleses e norte-americanos e no calvinismo missionário, conversionista, conservador e pietista norte-americano do século XIX (MENDONÇA, 1995, p. 213-234). Os americanos e, em especial, os protestantes norte-americanos, no século XIX, eram representados no Brasil como pregoeiros do progresso científico e tecnológico, os heróis civilizadores. Os missionários reforçaram essa imagem e a veicularam em alguns meios intelectuais e políticos brasileiros (BASTOS, 1938). O Correio Mercantil, de 17 de maio de 1855, publica uma notícia importante sobre uma exposição industrial realizada por Fletcher, missionário presbiteriano, no Rio de Janeiro em 1844. A exposição industrial, aberta ao público por dois dias, foi um sucesso (KIDDER; FLETCHER, 1941; VIEIRA, 1980).

A 12 de agosto de 1859, a Igreja Reformada chega ao Brasil, no Rio de Janeiro, com Ashbel Green Simonton, missionário do norte dos Estados Unidos (RIBEIRO, 1973; 1981). 


\section{A educação missionária presbiteriana: uma escola ao lado de cada igreja}

A Bíblia era o epicentro do protestantismo, especialmente aquele de cunho calvinista, o qual deu origem à Igreja Presbiteriana no Brasil. A importância da leitura da Bíblia nos cultos desenvolveu nos missionários presbiterianos, no país, um gérmen de projeto educacional vinculado à evangelização. Ashbel Green Simonton (1867), missionário fundador da Igreja Presbiteriana do Brasil, apresenta ao Presbitério do Rio de Janeiro uma tese, na qual afirmava que um dos métodos adequados para a evangelização do Brasil era a fundação de escolas paroquiais: uma escola ao lado de cada igreja. Em 1870, segundo o censo, na cidade de São Paulo, $92 \%$ da população era constituída de analfabetos. A visão de Simonton sobre a educação brasileira era realista. Primeiro, era necessário educar, para depois evangelizar (SIMONTON, 1867, p. 4). Não era possível, do ponto de vista protestante, evangelizar analfabetos.

É de confessar que a educação há de encontrar grandes obstáculos provenientes de muitas causas. Muitos pais de família são descuidados a este respeito, nem querem fazer os sacrifícios preciosos para educar os seus filhos. Estes de sua parte, não estando acostumados a obedecer a seus pais, não gostam do regime da escola bem dirigida. Os costumes do país e a falta de confiança não permitem que uma escola central seja freqüentada por todos como sucede nos Estados Unidos. Faltam professores e professoras com a prática necessária para bem desempenharem esta missão e o governo ainda não admite a instrução e educação da nova geração. Sendo este meio indispensável, temos razão para esperar que Deus nos deparará os meios de atingi-los (SIMONTON, 1867, p. 4).

No protestantismo calvinista, a fé equivale a conhecimento. E conhecimento que nasce da leitura teológica da Bíblia. O projeto educacional de Simonton terá como objetivo atender a essas necessidades missionárias da igreja e da evangelização:

Outro meio indispensável para assegurar o futuro da igreja evangélica no Brasil é o estabelecimento de escolas para filhos de seus membros. Em outros países, é reconhecida a superioridade intelectual, e moral da população que procura as igrejas evangélicas: o Evangelho dá estímulo a todas as 
faculdades do homem e o leva a fazer os maiores esforços para avantajarse nas sendas do progresso. Se assim não suceder entre nós, a culpa será nossa. Se a nova geração não for superior à atual, não teremos preenchido o nosso dever (SIMONTON, p. 4).

Essa necessidade de instrução do povo é uma premência também da própria liturgia calvinista, calcada na tradição escrita da leitura dos textos bíblicos e de longas litanias, assim como nos cânticos congregacionais.

Além disso, o próprio culto protestante exige a leitura, pois o seu material litúrgico é a Bíblia e o livro dos hinos. Para atender a esta necessidade, os missionários colocaram, ao lado de cada comunidade, uma escola. Estas foram as escolas paroquiais, alfabetizadoras e elementares (MENDONÇA, 1995, p. 97).

No último quartel do século XIX, os missionários presbiterianos fundaram cerca de sessenta escolas presbiterianas, somente nos Estados do Sudeste, todas com a mesma finalidade: ensinar o povo a ler, para poder ler e compreender os ensinamentos bíblicos contidos nas Sagradas Escrituras (ALBINO, 1996).

A cosmovisão presbiteriana obrigou no Brasil a prática protestante, desenvolvida na Europa e nos Estados Unidos, de fundar uma escola ao lado da igreja, onde quer que se formasse um núcleo de convertidos, a fim de ensiná-los a leitura da Bíblia. Fundaram-se escolas paroquiais no Rio de Janeiro, Brotas - São Paulo, Campinas - São Paulo, São Paulo - São Paulo, Borda da Mata - Minas Gerais, São João do Rio Claro São Paulo, Lorena - São Paulo, Petrópolis - Rio de Janeiro, Salvador - Bahia; escolas foram criadas em Pernambuco, e em outros lugares menos citados, todas com a mesma finalidade: ensinar o povo a ler para poder compreender os ensinamentos bíblicos contidos nas Sagradas Escrituras. O mesmo projeto dos missionários presbiterianos do norte foi tentado pelos imigrantes sulistas que fundaram o Collegio Internacional de Campinas em 1869 e inauguraram-no em 1873. As Escolas iam sendo fundadas onde eram plantadas as igrejas, assim os presbiterianos reproduziam a sua visão de mundo e produziam seus sistemas de vida por onde quer que se implantassem no Brasil.

Além das primeiras letras, ensinava-se a Bíblia e o Breve Catecismo. Havia culto diário, com oração e cântico de hinos. A escola ao lado de cada 
igreja destinava-se a suprir a ineficiência do sistema pedagógico nacional, bem como, onde fosse o caso, prevenir conflitos, que poderiam resultar da imposição de práticas católicas romanas às crianças protestantes.

Estas escolas presbiterianas foram sustentadas pela missão norteamericana no Brasil, como se depreende do orçamento missionário abaixo.

Os orçamentos da Brazil Mission, ao longo dos anos, invariavelmente destinam verbas para as escolas.

Campo do Rio de Janeiro - Escola .1:000\$000; Campo da Bahia e Cachoeira — Escola...............1:200\$000; Campo de Rio Claro — Escola, internato para órfãos e pobres.....5:700\$000; Campo de Sorocaba Escola. $400 \$ 000$;

Campo de Botucatu - Escolas..............2:368\$000; Campo de Campos (RJ) - Escola.............. 600\$000; Campo de Brotas - Escola...................1:000\$000; Campo de S. Paulo Escola. 8:700\$000 (RIBEIRO, 1981, p. 190-192).

\section{A Escola Americana e o Mackenzie College}

Em São Paulo, o projeto educacional de Ashbel Green Simonton foi transformado em realidade por George Chamberlain, com a fundação da Escola Americana. A tradição afirma que, no ano de 1870, na cidade de São Paulo, a esposa do missionário presbiteriano norte-americano Dr. George W. Chamberlain, Mary Annesley Chamberlain, funda, em sua própria casa, uma pequena escola primária para atender aos alunos presbiterianos e alguns filhos de republicanos e de abolicionistas, judeus e maçons. Essas crianças, pelas suas origens ideológicas, estavam impossibilitadas de frequentar as escolas públicas e outras, por motivos de intolerância religiosa e política (LESSA, 1938; GARCEZ, 1970). A Escola Americana ou Colégio Protestante é o berço da Universidade Presbiteriana Mackenzie (UPM) e do Sistema Mackenzie de Ensino (ASSIS, 1997).

Horace Lane, diretor do Colégio Protestante de São Paulo, apela para os seus amigos em Nova York para a criação de um College Protestante em São Paulo. Já no ano de 1889, uma comissão de homens de negócios e educadores norte-americanos visitara São Paulo e recomendara o 
estabelecimento de cursos universitários suplementares à Escola Americana voltados para o comércio e a indústria (STEWART, 1932, p. 26).

A Universidade do Estado de Nova York concedeu carta de privilégio ao Mackenzie College, em 2 de novembro de 1895, substituindo a que fora dada, a título de experiência, em 9 de fevereiro de 1893, subordinando a colação de grau a parecer favorável, em cada caso particular, daquela Universidade. O Diploma passa a ser concedido pela Universidade do Estado de Nova York. O Mackenzie College permaneceu ligado à Universidade do Estado de Nova York até 1952 (LANE, 1897; MENDES, 2005).

A influência do Mackenzie College na formação da mentalidade de uma elite empresarial, em São Paulo, entre 1870 e 1914, ocorreu de forma sistemática, por meio do Curso de Comércio e do Curso de Engenharia. Nestes cursos, os rudimentos da economia pragmática, capitalista e liberal eram fartamente ensinados e, pela primeira vez, aqueles alunos interessados nos negócios da nação aprendiam a separar o lucro do capital. Esses alunos, depois de formados, foram pioneiros na administração racional de empresas públicas e de empreendimentos privados. Por outro lado, convém lembrar que, por mais de cinquenta anos, a Escola de Engenharia do Mackenzie College formou mais da metade de todos os engenheiros registrados no CREA de São Paulo até 1960, como observou Mendes (1999).

A contribuição do Mackenzie College na formação da mentalidade do empresariado em São Paulo deu-se pela preparação de mão de obra adequada à administração do capital, segundo os postulados da cultura protestante evidenciados por Weber (1994). Esse College agiu ainda como um polo irradiador da filosofia industrialista norte-americana, através do Instituto de Desenvolvimento da Organização Racional do Trabalho (IDORT) e do desenvolvimento, nos egressos da Escola de Engenharia, do espírito empreendedor, o qual fez germinar o moderno capitalismo ocidental (OLIVEIRA, 1997).

As escolas presbiterianas foram analisadas por Jether Pereira Ramalho (1976), que considerou duas variáveis: o espírito protestante trazido pelos missionários presbiterianos e a práxis pedagógica das escolas presbiterianas. Ramalho observou o espírito protestante existente nas escolas presbiterianas, a partir da relação que havia entre o liberalismo e o pietismo protestante, nos seguintes aspectos: Individualismo - Uma 
das doutrinas básicas do protestantismo, que toma ênfase especial no pietismo, é a que se refere à responsabilidade individual do sujeito diante de Deus. Cada um é responsável pela sua própria salvação. Liberdade - Essa categoria está presente na origem do movimento histórico que redunda no protestantismo, sendo muito enfatizada no pietismo. Nas suas bases estão as afirmações do direito de livre interpretação da Bíblia e a doutrina do Livre Exame. Democracia - também sobre a forma de governo havia certa coincidência entre o pietismo e o liberalismo: os missionários e suas escolas eram republicanos. Trabalho e êxito - Para os pietistas, o trabalho constitui, antes de mais nada, a própria finalidade da vida (vocação). Viver para a glória de Deus é viver para o trabalho. O êxito no trabalho significa que Deus está abençoando suas atividades. Progresso - A ideia de progresso ininterrupto coadunou-se com os ideais de progresso das forças armadas brasileiras da Primeira República (RAMALHO, 1976, p. 100-150).

Antonio Maspoli de Araújo Gomes (2000) relaciona as contribuições do Mackenzie College à educação brasileira: a) o ensino da racionalidade do espírito protestante, decantada por Max Weber (1994) em sua obra A ética protestante e o espírito do capitalismo; b) o pragmatismo protestante como práxis educacional: o pragmatismo derivado da racionalidade metódica do protestantismo produziu uma educação voltada para aplicações práticas, como a educação para o comércio e indústria; c) o pioneirismo na educação de mulheres e a sua contratação como professoras nas escolas presbiterianas; d) a ausência total de castigos físicos nas escolas, com a utilização de reforços positivos como um facilitador da aprendizagem, transformando-a numa a atividade lúdica; e) o uso do método silencioso, indutivo, com a primazia da inteligência sobre a memória, fato que a escola brasileira, pela média, desconhece até hoje (GOMES, 2000, p. 182186; GOLDMAN, 1972).

\section{Universidade Presbiteriana Mackenzie: do pragmatismo à confessionalidade}

A confessionalidade é implantada na Universidade pela reforma dos Estatutos da Universidade, em 1999, quando o nome Universidade Mackenzie é mudado para Universidade Presbiteriana Mackenzie. As 
causas dessa confessionalidade tardia são várias; todavia, destacaremos apenas três delas: a) as raízes históricas da confessionalidade da própria instituição mantenedora - representante do Associado Vitalício, a Igreja Presbiteriana do Brasil —, que, por força da sua confissão religiosa calvinista, a Confissão de Fé Westminster, assumiu a confessionalidade das suas origens; b) causas políticas - a experiência da desapropriação do Mackenzie pelo Governador Laudo Natel, em 1966, e a filantropia; c) a necessidade de explicitar sua identidade calvinista, presbiteriana.

As raízes históricas da confessionalidade da Universidade Presbiteriana Mackenzie encontram-se ligadas umbilicalmente às origens da Escola Americana ou Colégio Protestante. A Escola Americana deu origem ao Sistema Mackenzie de Ensino e à própria Universidade, por intermédio do Mackenzie College. O missionário presbiteriano, norte-americano criador da Escola Americana em São Paulo, George Chamberlain, funda uma escola evangélica: "Em seus argumentos junto a Missão de Nova York, Chamberlain ainda comenta que a escola fundada em São Paulo ministrará educação evangélica confessional nos moldes dos mais sagrados princípios de moral cristã protestante" (HACK, 2003, p. 58).

O regulamento do Mackenzie College, criado por Horace Lane em 1885, já prevê a confessionalidade no seu regulamento. Horace Lane, contudo, não era um homem da igreja, raramente assistia aos cultos e, aos domingos, preferia andar de charrete pela cidade de São Paulo a participar dos cultos da Igreja Presbiteriana de São Paulo ou da sua Escola Dominical. Lane jamais deu ênfase à confessionalidade (GARCEZ, 1970). O pragmatismo de Horace Lane será a marca da Universidade Mackenzie até a década de 1990. No modelo educacional adotado pela Universidade Mackenzie não havia lugar para a vocação religiosa confessional. A Universidade assume explicitamente a confessionalidade somente em 1999.

Quanto a Universidade, o tema era preocupação latente, mas sem medidas diretas, a não ser o oferecimento dos serviços de capelania ou de celebrações religiosas. Os líderes acadêmicos, desde os reitores, diretores de faculdades e corpo docente, não tinham compromisso religioso com os princípios da fé cristã reformada. A cultura universitária mackenzista afastou-se da tradição histórica, cuidando do progresso da vida acadêmica, sem nenhuma vinculação religiosa (HACK, 2003, p. 162). 
A inspiração para a confessionalidade da Universidade Mackenzie renasce, sem dúvida nenhuma, da inspiração calvinista do seu fundador, George Chamberlain, e mesmo da confessionalidade do Colégio Mackenzie. Na segunda metade da década de 1990, a universidade buscará, nas suas origens histórico-teológicas calvinistas, as bases da confessionalidade.

A partir de 1997, com ação conjunta da Chancelaria e Reitoria da Universidade, foi elaborado um projeto para sensibilizar a comunidade acadêmica. O diálogo com a entidade mantenedora permitiu mudanças estatutárias e a realização de eventos para discutir a história do Mackenzie e seu relacionamento com os princípios cristãos de uma teologia reformada calvinista (HACK, 2003, p. 163).

A Universidade Presbiteriana Mackenzie é uma intuição filantrópica, sem fins lucrativos, como todas as demais universidades comunitárias e confessionais. A definição por essa forma jurídica de existência remonta ao desejo dos fundadores e doadores da Universidade, a Igreja Presbiteriana do Brasil, em 1952. A mantenedora adotou a confessionalidade, por força das suas origens calvinistas, desde a sua fundação. O colégio mantinha-se confessional. Só a universidade estava indefinida quanto à confessionalidade. Tal indefinição custara caro, no passado recente, quando o governador de São Paulo, Laudo Natel desapropriou a Universidade Mackenzie e estatizou todo o complexo Mackenzie de ensino, no Estado de São Paulo, pelo Decreto Estadual n ${ }^{\circ}$ 47.379 de 16 de dezembro de 1966. Por força de uma Ação Popular, o Mackenzie só voltará para sua mantenedora, a Igreja Presbiteriana do Brasil, em 1968. Por outro lado, a confessionalidade coloca a Universidade Mackenzie no concerto das universidades comunitárias e confessionais, as quais, pela sua natureza filantrópica, gozam de alguns privilégios tributários (GARCIA, 1968, p. 1-32).

Grupos, organizações e instituições carecem de uma identidade para existir. Não se tem conhecimento de textos que tratam da identidade universitária. No entanto, aquilo que se diz do sujeito vale também para os grupos, na concepção de Antonio Ciampa (1986; 1987). Ciampa afirma que a identidade, considerada do ponto de vista psicológico, nasce a partir da interação do sujeito com a comunidade, a qual é tomada, no 
presente estudo, como o espaço privilegiado de interação do indivíduo com o outro, num determinado espaço geográfico, por um longo período de tempo. Outra característica da comunidade é a existência de crenças, valores e objetivos comuns. Nesse sentido, a comunidade pode ser uma família, uma escola, uma igreja, uma instituição social, uma empresa, uma corporação de ofício, um sindicato etc. A identidade do sujeito, nesse âmbito, vincula a sua existência social ao contexto de uma comunidade. A comunidade que tem identidade gera a identidade do sujeito. A identidade comunitária surge dentro de um contexto maior (CIAMPA, 1985, p. 64).

Antes da confessionalidade, a identidade da Universidade Mackenzie oscilava entre o pragmatismo e a fé reformada. A Universidade expressava suas crenças, seus valores e sua ideologia de forma implícita e difusa. Do ponto de vista político, isso em nada contribuía para a práxis educacional do corpo docente nem para a transmissão de valores centenários acumulados em mais de um século pela cultura mackenzista. A confessionalidade explícita da universidade daria consistência à identidade calvinista do seu projeto educacional. Na justificativa para a confessionalidade da Universidade Presbiteriana Mackenzie, o então chanceler Osvaldo Henrique Hack arrola um conjunto de fatores que devem nortear a identidade de uma universidade confessional. "A identidade das universidades confessionais passa pela coerência de seus princípios e de sua prática metodológica, propondo um ensino de qualidade acadêmica com valores religiosos para constituir uma nova realidade social" (HACK, 2003, p. 166).

A partir da adoção da confessionalidade, a identidade confessional da Universidade deve ser expressa em seus documentos legais: Estatutos, Regimentos e no Projeto Pedagógico (HACK, 2003, p. 167). "Portanto, um projeto pedagógico embasado na tradição reformada, calvinista, coerente com as origens mackenzistas, deve levar a instituição a promover uma educação voltada para a cidadania" (HACK, 2003, p. 173; SANTOS JUNIOR, 2007).

A transformação da Universidade Presbiteriana Mackenzie em Universidade Confessional foi precedida de longos e intensos debates realizados pela reitoria do professor doutor, Cláudio Salvador Lembro. Os debates foram denominados de Colóquios. Ao longo de dois anos foram realizados doze Colóquios. Nestes Colóquios buscava-se compreender 
a filosofia reformada de educação. Os professores participaram intensamente destes Colóquios, que funcionaram como uma espécie de audiência pública. No entanto, por se tratar de uma universidade comunitária, os debates foram marcados pelo comedimento do corpo docente (HACK, 2003).

O foco de maior preocupação do corpo docente não era a confessionalidade, mas a manutenção dos espaços conquistados ao longo de mais de cem anos! Tais espaços foram garantidos pela reitoria. A confessionalidade representava uma mudança na filosofia educacional da intuição, não nas relações institucionais e trabalhistas. Ficou estabelecido por um acordo de cavalheiros que a confessionalidade seria exercida pela missão da universidade, não pela sua função. Quando o Conselho Universitário aprovou a mudança do nome de Universidade Mackenzie para Universidade Presbiteriana Mackenzie, o fez pela unanimidade dos votos dos seus membros (HACK, 2003).

Ainda não foram realizadas pesquisas sobre o impacto da confessionalidade sobre o corpo docente e discente da Universidade Presbiteriana Mackenzie. No entanto, a pesquisa de campo pode inferir algumas observações. Quando da implantação da confessionalidade, em 1999, havia mil professores no corpo docente. Deste total, apenas cinco eram vinculados a algum ramo do protestantismo. Já no ano 2000, com a criação da Escola Superior de Teologia e do Programa de Pós-Graduação em Ciências da Religião, esse número havia saltado para 36 docentes vinculados à fé cristã protestante, de um total de 1.200 professores.

Registra-se, todavia, que os professores protestantes foram contratados para compor o corpo docente do curso de teologia, criado em 1999, e do programa de Pós-Graduação em Ciências da Religião, criado no ano 2000, portanto, não ocuparam os espaços de outros professores da universidade (GOMES, 2007). A Universidade Presbiteriana Mackenzie buscou doutores protestantes das mais diversas áreas para seus quadros; no entanto, não os encontrou no mercado. Os doutores das mais diversas áreas da ciência e do conhecimento em geral vinculados ao protestantismo no Brasil naquele momento ainda eram escassos.

A confessionalidade foi implantada em 1997, ao mesmo tempo em que foram criados dez programas de pós-graduação na Universidade Presbiteriana 
Mackenzie. Nesse momento foram contratados sessenta professores doutores de tempo integral (PPI) para os Programas de Pós -Graduação. Isso de certa forma ofuscou perante o corpo docente as questões relacionadas à confessionalidade por uma questão maior: a pós-graduação.

Quanto ao corpo discente, a reitoria encomendou em 1999 uma pesquisa sobre a filiação de seus alunos. Naquele instante a universidade contava com 30.000 alunos. Desse total, apenas 5\% professava algum tipo de protestantismo histórico e/ou emocional-pentecostal.

Ainda não foram realizadas outras pesquisas sobre este universo depois do advento da confessionalidade. Atualmente, em 2015, contudo, de um total de 41.000 alunos, existem seiscentos somente no curso de teologia, no Programa de Ciências da Religião. Estes estudantes são em quase sua totalidade vinculados a alguma confissão protestante e/ou pentecostal (GOMES, 2007).

O curso de teologia, criado em 15 de setembro de 1999 por este pesquisador para expressar a confessionalidade de matriz calvinista, atraiu especialmente alunos pentecostais e neopentecostais.

O espaço da Teologia no Brasil sempre foi demarcado pelo aspecto da confissão religiosa. Cada denominação mantém cursos de teologia próprios, em seminários, para formar a sua liderança eclesiástica. A entrada da Teologia na universidade mudou essa realidade. A Escola Superior de Teologia da Universidade Presbiteriana Mackenzie atraiu majoritariamente alunos evangélicos (95,6 \%), sendo 30\% constituídos de presbiterianos e $70 \%$ de pentecostais e neopentecostais, e poucos alunos de outras tradições religiosas (2,1\% de católicos, 1,4\% de espíritas e $0,7 \%$ de judeus) (GOMES, 2016, p. 42). Disso se depreende que as demais confissões religiosas são absolutamente respeitadas dentro da visão confessional da Universidade Presbiteriana Mackenzie.

Se considerarmos que a Universidade Presbiteriana Mackenzie não parou de crescer depois da confessionalidade, podemos afirmar que a transformação da filosofia da universidade, do pragmatismo para o calvinismo, pode ter sido um fator positivo em sua história.

Implantou-se a confessionalidade na Universidade Presbiteriana Mackenzie tendo como pressuposto básico o testemunho da fé cristã 
reformada, por meio da educação e do respeito absoluto à dignidade da pessoa humana, em sua diversidade de crenças religiosas (SANTOS JUNIOR, 2007).

Institucionalmente a confessionalidade expressa-se na Visão da Universidade: "Educar o ser humano, criado à imagem de Deus, para o exercício pleno da cidadania, em ambiente de fé cristã reformada" (UPM, 2016). A confessionalidade expressa-se também na missão da universidade: "Ser reconhecida pela sociedade como instituição confessional presbiteriana e filantrópica, que se dedica às ciências divinas e humanas, comprometida com a responsabilidade socioambiental, em busca contínua da excelência acadêmica e de gestão" (UPM, 2016).

Além de disso a confessionalidade expressa-se também por intermédio do serviço de capelania, subordinado à chancelaria, atualmente com dez capelães. Expressa-se por meio do curso de teologia e pela disciplina de Ética e Cidadania.

A disciplina de Ética e Cidadania, obrigatória para todos os cursos de graduação da Universidade, ensina o pensamento calvinista em suas relações com o sujeito e a sociedade, revelando o pensamento teológico, político, econômico, científico, social e ecológico do protestantismo reformado.

O objetivo final da disciplina, no entanto, não é a conversão do aluno ao pensamento protestante reformado, haja vista que a universidade respeita as crenças de seus professores e alunos. O alvo desta disciplina é formar o cidadão responsável dentro da perspectiva calvinista de respeito à dignidade da pessoa humana para se atingir o bem comum. "Educação para o amor ao próximo que se expressa de forma objetiva em ações concretas e participação responsável na construção da cidadania e do bem estar da coletividade e da comunidade" (GOMES; HACK, 2002, p. 55). Esta filosofia concretizou-se posteriormente nos valores e princípios da universidade: "Na sociedade: participação e prestação de serviços à comunidade; E, em todas as circunstâncias, agir com amor que é o vínculo da perfeição" (UPM, 2016).

\section{Considerações finais}

A Escola Americana nasce de uma escola missionária presbiteriana, em São Paulo, em 1870. Em suas origens, é uma escola paroquial, visando à 
educação para a evangelização, segundo o modelo da Reforma protestante: uma escola ao lado de cada igreja. A Escola Americana, que deu origem ao atual Colégio Mackenzie e ao Sistema Mackenzie de Ensino, desde a sua fundação, manteve a sua confessionalidade calvinista, presbiteriana, como forma de ensino. A Bíblia é utilizada até hoje no processo de alfabetização de crianças e adultos, por exemplo (CORREA, 1980).

O Mackenzie College, criado oficialmente em 1885, por um grupo de homens de negócios do Estado de Nova York, pela Carta de Privilégios concedida pela Universidade do Estado de Nova York, passa a integrar o complexo educacional norte-americano denominado Universidade do Estado de Nova York, em 1893. O College surge, portanto, de um projeto pragmático com uma proposta confessional implícita em seus objetivos (GOMES, 2000).

A Universidade Mackenzie, herdeira natural do Mackenzie College, é nacionalizada em 1952. Contudo, seu projeto de confessionalidade explícita, tardio, toma corpo apenas na segunda metade da década de 1990. A confessionalidade é implantada pela reforma dos Estatutos da Universidade, em 1999, quando o nome Universidade Mackenzie é mudado para Universidade Presbiteriana Mackenzie.

Em consonância com a tradição da cultura mackenzista, a confessionalidade da Universidade Mackenzie está implantada sobre os pressupostos do testemunho da fé cristã reformada, em absoluto respeito à dignidade da pessoa humana, em sua diversidade de crenças religiosas e políticas.

Considerando-se que a confessionalidade foi implantada há apenas dezesseis anos, ainda é relativamente cedo para se proceder a uma avaliação do impacto desta confessionalidade tardia sobre o corpo docente e discente. Outras pesquisas poderão inclusive, verificar, por exemplo, qual o impacto da confessionalidade no perfil religioso do aluno e do professor. 


\section{Referências}

ALBINO, M. "Ide por todo mundo": a província de São Paulo como campo de missão presbiteriana - 1869-1892. Campinas: Centro de Memória da UNICAMP; São Paulo: FAPESP, 1996.

ANDERSON, W. K. et al. Espírito e mensagem do protestantismo. Trad. Nicodemus Nunes. São Paulo: Junta Geral de Educação Cristã da Igreja Metodista do Brasil, 1953.

ANDRESS, P. An Educational Approach to the Work of the protestant Church in Latin America. New York: Columbia University, 1951.

ASSIS, C. et al. Mackenzie 126 anos de ensino: valores acima do tempo. São Paulo: Instituto Presbiteriano Mackenzie, 1997.

BARBANTI, M. L. S. H. Escolas Americanas de confissão protestante na Provincia de São Paulo: um estudo de suas origens. 1977. Dissertação (Mestrado) — Faculdade de Educação, Universidade de São Paulo, São Paulo, 1977.

BASTOS, A. C. T. Carta do solitário. São Paulo: Companhia Editora Nacional, 1938.

BRENTANO, F. Martim Lutero. Trad. Eloy Pontes. 3. ed. Rio de Janeiro: Vecchi, 1968. (Coleção Vidas Extraordinárias).

CALVINO, J. Institución de la religión cristiana. Traducida y publicada por Cipriano de Valera en 1597 por Luis de Usoz y Río, en 1858. Nueva edición revisada en 1967. Países Bajos: Fundación Editorial de Literatura Reformada, 1967. v. I-v. II.

CIAMPA, A. da C. Identidade. In: Psicologia social, o homem e em movimento. 3. ed. São Paulo: Brasiliense, 1985.

CIAMPA, A. da C. A estória do Severino e a história da Severina. São Paulo: Editora Brasiliense, 1987.

CORREA, A. M. Lares, escolas e igrejas. Piracicaba: Rev. Erasmo Prese de Souza, 1980. GARCEZ, B. N. O Mackenzie. São Paulo: Presbiteriana, 1970.

GARCIA, H. O. M. O caso Mackenzie. São Paulo: Universidade Mackenzie, nov. 1968. 
GOLDMAN, F. P. Os pioneiros americanos no Brasil (educadores, sacerdotes, covos e reis). Trad. Olívia Krahenbüll. São Paulo: Pioneira, 1972.

GOMES, A. M. de A. Religião, educação e progresso. A contribuição do Mackenzie College para a formação do empresariado industrial de São Paulo entre 18701914. São Paulo: Mackenzie, 2000.

GOMES, A. M. de A. (Org.). Teologia, ciência e profissão. São Paulo: Fonte Editorial, 2007.

GOMES, A. M. de A. Teologia, ciência e profissão: educação teológica e a identidade profissional do teólogo no Brasil. In: GOMES, A. M. de A.; JOSÉ, G. de O. M.; ROSSI, L. A. S. Um olhar interdisciplinar sobre teologia e educação. São Paulo: Editora Reflexão, 2016.

GOMES, A. M. de A.; HACK, O. H. Reflexões sobre educação, ética e cidadania a partir do pensamento reformado. In: DE LIBERAL, M. M. C. Um olhar sobre ética e cidadania. (Coleção reflexões acadêmicas). São Paulo: Editora Mackenzie, 2002. v. I.

HACK, O. H. Protestantismo e cultura brasileira. São Paulo: Presbiteriana, 1985.

HACK, O. H. Raízes cristãs do Mackenzie e seu perfil confessional. São Paulo: Mackenzie, 2003.

IRWIN, C. H. Juan Calvino, sua vida y sua obra. México: Casa Unida, 1947.

KEY, J. S. The Rise and Development of Baptist Theological Education in Brazil, 1881-1963: a historical and interpretative survey. Fort Worth: Southwestern Baptist Seminary, 1965.

KIDDER, D. P.; FLETCHER, J. C. O Brasil e os Brasileiros (esboço historico e descritivo). Trad. Elias Dollianiti, rev. e notas de Edgard Sossekind de Mendonça. São Paulo: Nacional, 1941. v. I-v. II.

LANE, H. M. The Protestant College at S. Paulo and Mackenzie College. Folheto escrito para propaganda do estabelecimento entre os americanos. São Paulo: Mackenzie College, 1897.

LESSA, V. da C. T. Calvino, 1509-1564, sua vida, sua obra. São Paulo: Presbiteriana, 1938.

MALINOWSKI, B. Um diário no sentido estrito do termo. Trad. Celina Cavalcante Falck. São Paulo: Record, 1997. 
MENDES, M. A Escola de Engenharia "Mackenzie College" e a questão do reconhecimento (1932-1938). 1999. Dissertação (Mestrado em Educação, Arte e História da Cultura) — Universidade Presbiteriana Mackenzie, São Paulo, 1999.

MENDES, M. Mackenzie em Movimento: Conjunturas decisivas na história de uma instituição educacional. 2005. Tese (Doutorado) - Universidade de São Paulo, Faculdade de Filosofia, Letras e Ciências Humanas, São Paulo, 2005.

MENDES, M. Mackenzie em três séculos. São Paulo: Editora Mackenzie, 2013.

MENDONÇA, A. G. O celeste porvir, a inserção do protestantismo no Brasil. São Paulo: Aste, 1995.

QUARTIN, Y. O Mackenzie na Revolução Constitucionalista de 1932. São Paulo: Edicon, 1995.

RAMALHO, J. P. Prática educativa e sociedade, um estudo de sociologia da Educação. Rio de Janeiro: Zahar, 1976. (Coleção Ciências da Educação).

RIBEIRO, B. Protestantismo no Brasil monárquico. Aspectos Culturais de Aceitação do Protestantismo no Brasil (1822-1888). São Paulo: Pioneira, 1973.

RIBEIRO, B. Protestantismo e cultura brasileira: aspectos culturais da implantação do protestantismo no Brasil. São Paulo: Presbiteriana, 1981.

SANTOS JUNIOR, A. C. dos. A liberdade de organização religiosa e o estado laico brasileiro. São Paulo: Mackenzie, 2007.

SIMONTON, A. G. Os meios próprios para plantar o reino de Jesus Cristo no Brasil. Documento lido perante o Presbitério do Rio de Janeiro no dia 16 de julho de 1867. 1867.

SISK, L. C. The history of Agnes Erskine College in Brazil, 1904-1970. Nashville: Tem. Peabody Teachers College, 1974.

UNIVERSIDADE PRESBITERIANA MACKENZIE. Confessionalidade, Missão, Visão, Princípios e Valores. 2016. Disponível em: <http://up.mackenzie.br/a-universidade/ confessionalidade-missao-visao-principios-e-valores/>. Acesso em: 28 jul. 2016.

STEWART, C. T. Mackenzie college, Escola Americana - Notas sobre a sua história e organização. São Paulo: Mackenzie College, 1932. 
THEOPHILO JÚNIOR, R. Cartulário. São Paulo: Universidade Presbiteriana Mackenzie, 2002.

VIEIRA, D. G. O protestantismo, a maçonaria e a questão religiosa no Brasil. Brasília: Universidade de Brasília, 1980.

WEBER, M. A ética protestante e o espírito do capitalismo. 8. ed. São Paulo: Pioneira, 1994.

Recebido: 19/06/2016

Received: 06/19/2016

Aprovado: 30/07/2016 Approved: 07/30/2016 